\title{
Development of an Information-Based Online Foreign Language Teaching Platform with ASP.NET
}

\author{
https://doi.org/10.3991/ijet.v14i13.10711 \\ Lei Zhang \\ Jilin Institute of Chemical Technology, Jilin, China \\ goldenchina $79 @ 163 . \mathrm{com}$
}

\begin{abstract}
The online teaching platform is a major application of information-based education. If adopted for foreign language teaching, the platform can greatly facilitate the utilization of network resources and enhance the students' abilities in listening, speaking, reading and writing. This paper develops an information-based online foreign language teaching platform with the aid of ASP.NET. The SQL was selected as the backend database and accessed via ADO.NET. Taking the browser/server $(\mathrm{B} / \mathrm{S})$ structure was adopted as the network architecture, the platform was programmed in $\mathrm{C \#}$ and realized using Microsoft Visual Studio (VS) 2005. Through testing, the proposed platform was proved to achieve all expected functions and satisfy the demand of college English teaching in a safe and stable manner. The research findings promote the quality and informatization of English teaching.
\end{abstract}

Keywords-ASP.NET, SQL database, online foreign language teaching platform

\section{$1 \quad$ Introduction}

The rise of information network technology is a catalyst for constant innovation of the traditional teaching models. There is a surge of various new teaching technologies, for example, the online teaching platform is a modern education model developed rapidly in recent years [1]. As an international general-purpose language for foreign exchange, English has been arranged as a compulsory course in universities. How to design an online teaching platform that suits students to learn foreign languages in order to change the traditional teaching model in which students often act as passive learners and there is lack of chances for students to use English in teaching activities, and cultivate such English learners who excel in English listening, speaking, translating? It has been a global concern of experts and teaching workers in the education circles [2].

Information-based education has become a trend of the global education development, and some countries even tend to protect its important position by the form of legislation [3]. As one of greater online teaching platforms in foreign countries, WEBCT, developed by British Colurrbia in Canada for publishing the basic server programs relevant to teaching content and curriculum, is designed with data backup, 
security control, management, and other multiple functions [4]. Another major online teaching platform is the Blackboard, which supports access of tens of millions of users, and integrates Web-based education resources by taking the curriculum as its core. Each platform includes four standalone function modules, i.e. system management, assessment management, online communication and content resource management. Blackboard provides students and teachers with teaching and learning and online virtual environment where they can communicate with each other [5]. The Class Fronter e-learning platform developed by the Norwegian company provides more than 40 modules and enable several students to collaborate with each other on one file [6]. The development of information-based education system in China is 3-5 years later than that in foreign countries. Since 1999, China has integrated the curriculum education with the network technologies in different ways. Some universities and suppliers in China have developed or redeveloped the teaching platforms, such as the online teaching system for new concept English, Beijing Normal University's WebCL, etc. [7]. The Vclass is a set of Web-based teaching support platform, one of fully functional platforms developed for online education in China [8]. Although there are some more advanced online English education platforms currently available for matching various features in the R\&D areas in China, they still have their own defects, for example, they focus more on the stacking of functions, less on the learning environment layout, there is lack of teaching resources, slowly update, a poor platform openness, and restriction of student for self-learning, and other issues [9].

Given the above, this paper describes the R\&D of information-based English education platform with the ASP.NET technology. After the Introduction to the key technologies of platform development, this paper analyzes the function requirements of the platform and defines the platform structure that can be divided into three modules, i.e. teacher management and student learning and administrator management based on the objects used. In the end, here also describes the platform design and implementation in detail. Test results show that the platform is implemented with the expected function requirements, and good security and stability, well-fitting the needs of universities for English education.

\section{Key Technologies for Platform Development}

\subsection{ASP.NET technology}

JSP, PHP, and ASP are relatively mature Web-based development technologies and models, but now they have fallen short of what's needed in terms of business scalability, security, and operation speed [10]. ASP.NET is a part of the .NET Framework. As a universal Web development model, it separates the business logic from page logic when writing code. With all solutions for developing Web-based applications, it features simple development, high operation efficiency, and concise program structure [11]. The operating principle of ASP.NET is shown in Figure 1. Users send the request to the web server, which is sent to the ASP.NET engine via the 
appropriate .dll file. After processing via the HTTP, the request files and HS will be returned to users [12].

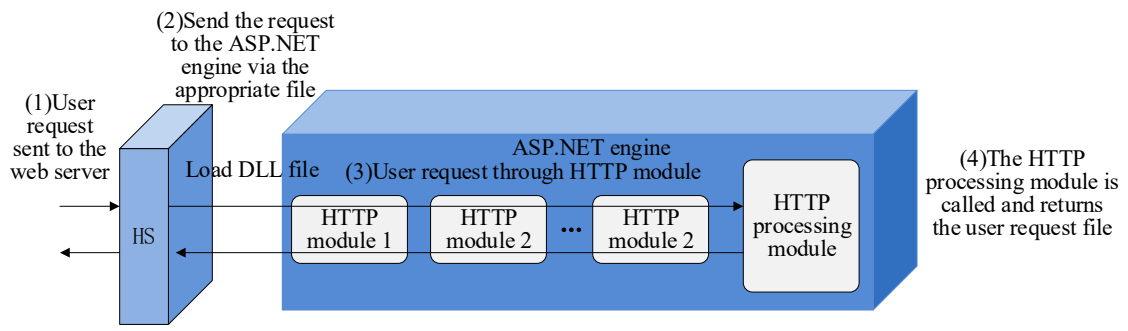

Fig. 1. ASP.NET operating principle

\subsection{SQL database}

SQL server is a relational database management system based on the Structured Query Language (SQL). It enables online analytical and distributed data processing functions, and has data warehouse and distributed database [13]. The said SQL, proposed by Boyce and Chamberlin in 1974, is a general-purpose integrated relationship database language enabled with data control, data definition, data query and other functions [14]. SQL data operations are highly DE procedural, that is, a request can be directly made, no need to understand the access path [15]. It is because of these features of SQL that it has become an international standard.

\subsection{Method of accessing database via ADO.NET}

ADO.NET is a data access model, and users can access data via the database interface ADO.NET at the business logic layer [16]. ADO.NET uses DataSe datasets and .NET data providers to access and process data. As shown in Figure 2, the process of data access achieved via ADO.NET technology is given [17].

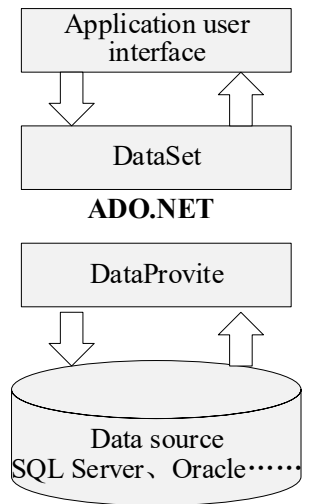

Fig. 2. The process of data access through ADO.NET technology 


\section{Design and Implementation of Inform-Based Online Foreign Language Teaching Platform Based on ASP.NET}

\subsection{Platform design objective}

The information-based online teaching platform for foreign languages is designed to provide a more attractive teaching and learning platform for teachers and students, in order to make up for the gaps of traditional platforms such as the shortage of classroom teaching resources and limited teaching time, allow students to preview before class, review after class, arouse students' interests in learning with abundant teaching resources, and cultivate students' awareness of self-directed learning [18]. In addition to these, the platform can also help consolidate the classroom teaching effect and facilitate the communication between teachers and students. Students and teachers as its primary users can access the platform via a LAN or the Internet [19].

\subsection{Analysis of platform requirements}

Functional and non-functional requirements are the two key components of platform requirements analysis. The specific analysis is as follows:

Non-functional requirements: The non-functional requirement of the platform will have a direct bearing on the performance and implementation of platform functions, mainly including the scalability, reliability, security, maintainability, and other performance indicators [20], as shown in Figure 3.

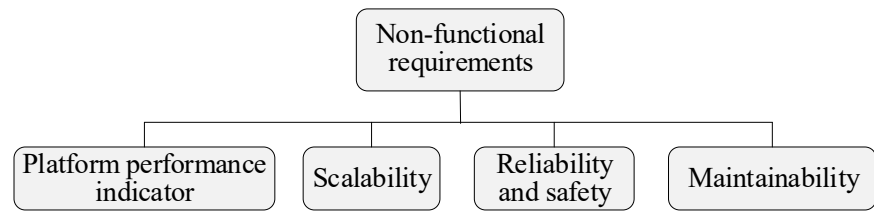

Fig. 3. Non-functional requirements of the platform

Functional requirements: To respond to the platform design objectives and carter for the needs of teachers and students for "teaching" and "learning" something, the platform should be designed to include the teaching and learning, teaching resources, homework management, FAQ, and self-testing modules [21], as shown in Figure 4.

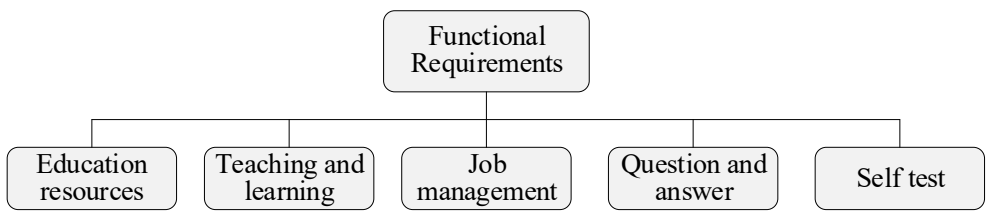

Fig. 4. Platform function requirements 
Teaching and learning: After the students log in the platform with user authentication successfully, they are allowed to browse relevant teaching resources uploaded by the teachers, and select appropriate contents to be learned according to the chapter title navigation options, thus fitting students' needs for preview before class and review after class [22].

Teaching resources: Those teaching resources in the platform can make up for the shortage of classroom resources and incomplete demo to provide a real learning environment for students to learn foreign languages. After the teachers log in the platform, they can upload, modify, delete videos, audio, images, texts, and other relevant materials; while students can browse or download relevant teaching resources online on demand.

Homework management: Teachers can post the assignments to students via the platform, and review and make statistics on the assignments. The assignments can be diversified, covering listening, speaking, reading, writing, translating practices, assigned via this function, thus breaking the traditional models in which, the homework is only writing- and translating-based [23]. Students can submit directly after finishing the assignments online, or upload the assignments finished offline, depending on the types of assignments. They can also view the teacher's review on the assignments and the grade of their assignments.

$F A Q$ : In order to timely solve the problems that the students encounter in the learning process, FAQ module is set up on the platform. If problems occur on students, they can first search for it by keywords in the FAQ module so that relevant questions and answers will be hit. In this way, the problems occurred can be answered in time, to lessen the workload of the teachers [24]. If questions and answers relevant to it are not found, students can raise the questions in the FAQ module, then other students will be involved to discuss it, and teachers will also respond to it in a timely manner.

Self-testing: Students can use the Self-test function to take an exam by selecting one or more chapters according to their own learning schedule and situation. The platform will automatically generate the test papers with certain difficulty and quantities as required in line with the selected chapters [25]. After students finish the exam, the test results and correct answers will automatically display to help students know how well they master the knowledge and timely check where they are weak.

\subsection{Design and implementation of platform}

Design of function module: Based on the analysis of platform requirements, as required for platform maintenance and management, the platform can be divided into three modules: administrator, students and teachers according to users. Figure 5 shows the functional structure of the platform [26]. 


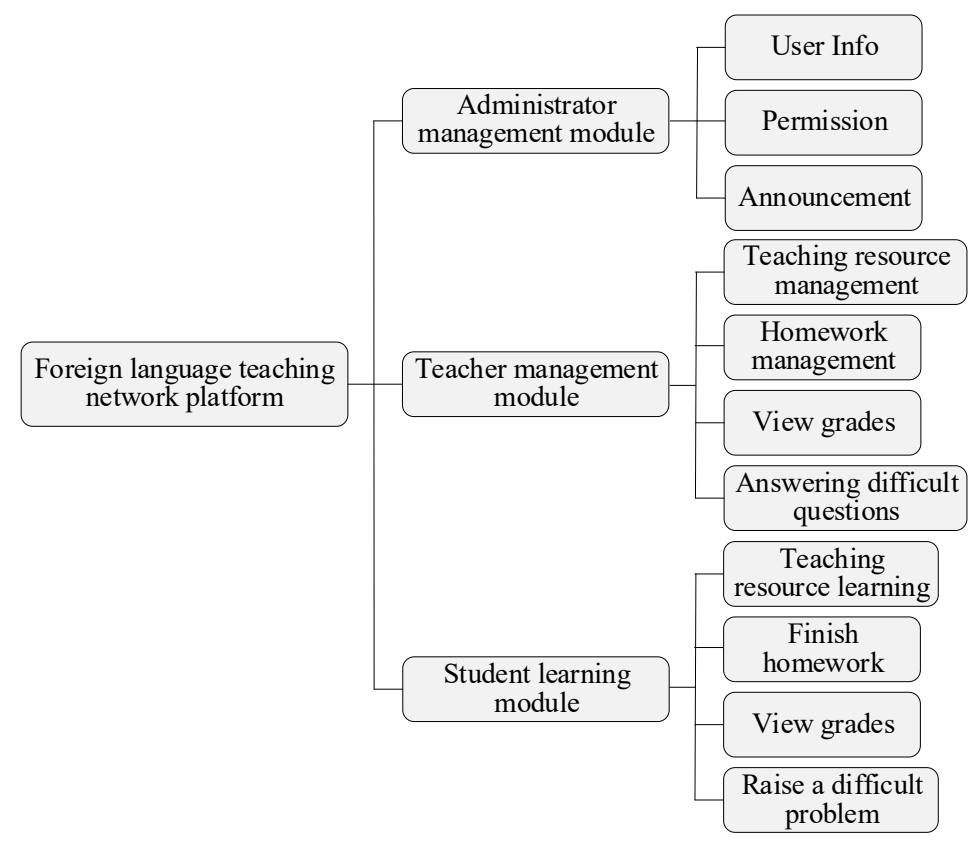

Fig. 5. System function structure diagram

Administrator management module: The administrator management module allows the administrator to add, modify, delete, and query the information of the users after he or she logs in the platform. Because the access rights are different, users may enter different interfaces with diverse functions after logging in the platform. Therefore, the administrator can set and modify the access rights for the users in the light of the actual situation [27]. To facilitate users to understand the major dynamic conditions, curriculum arrangements and teaching situations, the administrator can add, modify and delete relevant bulletin information, and send it to appropriate users for their review.

Teacher management module: This module mainly facilitates teachers to manage and maintain the teaching resources, publish the assignments, receive the assignments submitted by students and give comments on them, make statistics and analysis and publications on the students' academic records, and answers the FAQs for the students.

Students' learning module: After entering the platform, students can learn and download relevant resources, finish the assignments from the teachers and upload them, look through the teachers' comments on their assignments, and discuss with teachers and classmates the puzzling problems occurred in the learning process.

\section{Implementation of main module functions}

Platform management module: Platform administrator can add student and teacher users and maintain their information. As shown in Figure 6, in the Add teacher interface, the platform administrator can click the Add teacher button to populate the Teacher name, Teacher number, User name and Password fields after entering the 
management interface. In order to avoid repetition of user names, the platform also provides automatic detection on the user name. After adding successfully, the teacher can $\log$ in the platform as per the initial settings. To ensure the security, the login password can be changed. Refer to Figure 7 for the process of adding teacher information [28].

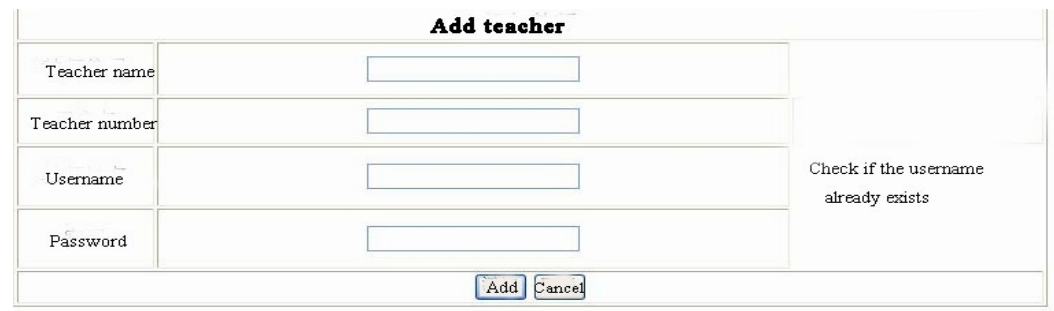

Fig. 6. Add teacher interface

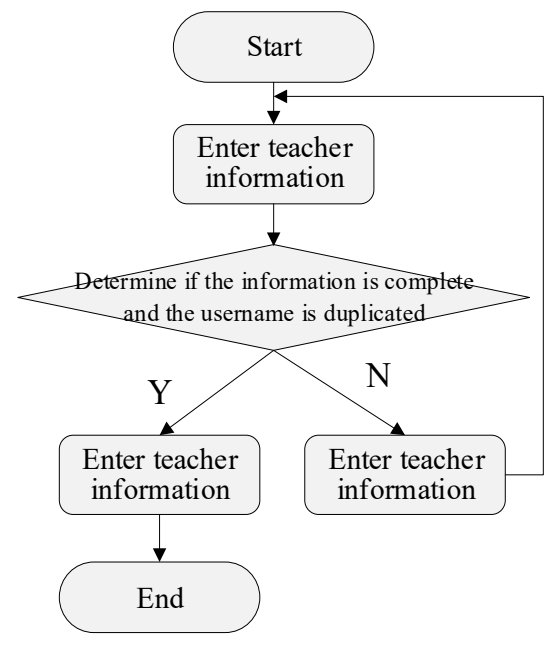

Fig. 7. Add teacher information process

Teacher management module: The functions of this module are described above. Here, the homework management function is instantiated to introduce how its functions are designed and implemented. Figure 8 shows the Post homework interface for teachers to publish the assignments. After the teacher logs in the platform, the following interface pops up when the Post homework is selected. Then the teacher selects the course title, inputs the job title, and the detailed requirements in the Content bar. In addition, the previously prepared homework documents can be uploaded in the form of attachment for the students to review it. Figure 9 gives the main process of publishing the homework by teachers. 


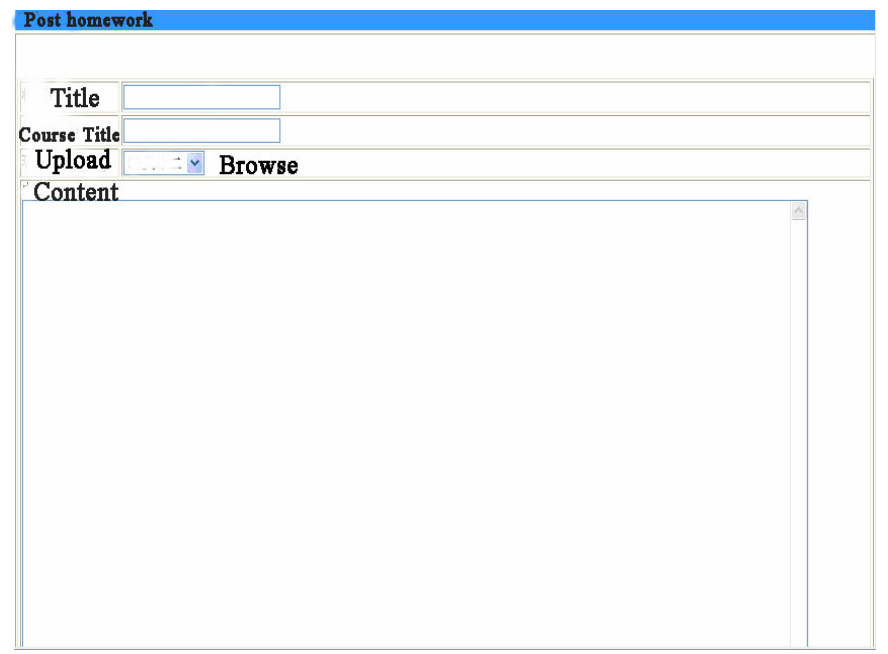

Fig. 8. Teacher user release job interface

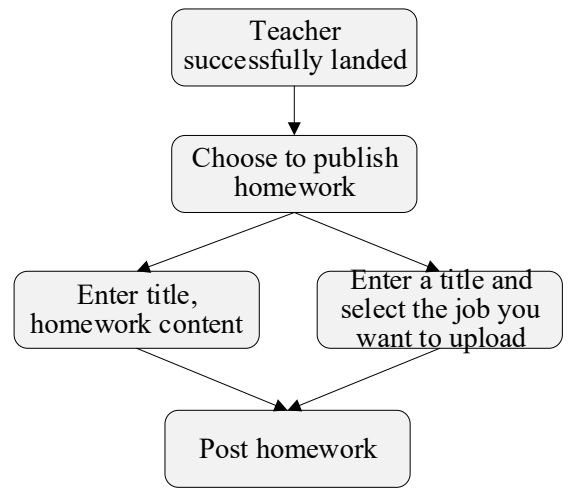

Fig. 9. The main process of the teacher's release of the assignment

Students' learning module: After the students enter the platform, they can browse the course information and teaching resources, finish the homework published by the teachers, interact with others in the FQA discussion area, and complete the self-test. As shown in Figure 10, after the students enter the Self-test interface, they can follow the tips to select the question type, difficulty level and test range. After it is selected, click Start the test, the platform will automatically generate the test papers, display the quizzes. As shown in Figure 11, it is the interface where the test papers generate in the platform according to the student settings. 


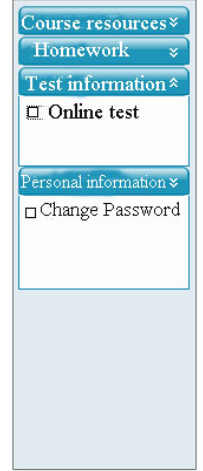

English self-test

\begin{tabular}{r} 
English self-test \\
\hline Please select test parameters \\
Test chapter Comprehensiver \\
Question type Automatic \\
Difficult \\
\\
\\
\end{tabular}

Fig. 10.Student self-test interface

1. What do you know about kite surfing? - It is
A. a exciting water an
C. the

D. /

2. Annie has and she

D. toothache

A. cold

B. fever

C. cough

on who is

does not tell lies or cheat people.

A. careless

B. stupid

C. honest

4. Mr. Smith has a habit of taking a shower __ he has breakfast.

A. though

B. before

C. because

ff the

my way to schoo

A. Luckily $\quad$ B. Suddenly

I wasn't hurt.

6. - Jenny, I Politely

- Wonderful! I can't wait to ___ it.

A. repeat

B. forget

C. receive

D. humorous

D. since

D. Recently

Fig. 11.Student paper interface

Platform test: To verify whether the various functions designed in the platform can be implemented as required in the design, and whether the platform can run stably and securely, this paper conducts the tests on the links, forms, database and data verification, as well as security and pressure, on the well-designed platform. The results show that the various functions including user authentication, uploading and downloading of files and the homework, exams for students can meet the requirements for functions in the design, and the platform is simple to operate, beautiful in interface, better in security, so that it will be able to meet the needs for education in foreign languages.

\section{Conclusion}

Following the ideas and methods of modern software engineering, this paper describes the development of the information-based online foreign language teaching platform based on ASP.NET technology. Here are concrete conclusions:

- From the functional and non-functional perspectives, this platform is analyzed in detail, and it is determined that there are five main functional requirements for the platform. 
- Based on the analysis of platform requirements, the platform is divided into three functional modules, i.e. teacher management, student learning and administrator management, based on the objects used. The design and implementation of individual function modules are elaborated.

- The functions, performance and security of the platform are tested. It is therefore proved that the platform can respond to the expected design objectives and well fit the needs for education in foreign languages

\section{Acknowledgement}

This article is a periodical achievement of the Social Science Project of the 13th "Five-Year Plan" of Jilin Provincial Department of Education-Cultivation of English Majors' Innovative and Entrepreneurial Ability in the Information Age (Grant No. JJKH20190841SK); Major Social Science Project of Jilin Institute of Chemical Technology---the Cultivation of the Innovative Ability in Foreign Language Talents of Applied Undergraduate Colleges in the Big Data Age (Grant No. 2018033).

\section{References}

[1] Richardson, W.K., Segal, D.M. (1998). Teaching analysis of interaction in the $2 \times 2$ factorial design. Teaching of Psychology, 25(4): 297-299. https://doi.org/10.10 $\underline{\text { 80/00986289809709722 }}$

[2] Velthuis, C., Fisser, P., Pieters, J. (2015). Collaborative curriculum design to increase science teaching self-efficacy: a case study. The Journal of Educational Research, 108(3): 217-225. https://doi.org/10.1080/00220671.2013.878299

[3] Jyothirmayi, R. (2012). Case-based discussion: assessment tool or teaching aid? Clinical Oncology, 24(10): 649-653. https://doi.org/10.1016/j.clon.2012.07.008

[4] Sweidan, S.Z., Darabkh, K.A. (2015). A new efficient assembly language teaching aid for intel processors. Computer Applications in Engineering Education, 23(2): 217-238. https://doi.org/10.1002/cae.21591

[5] Klatt, D.H. (1969). Computer-controlled display for second language learning. The Journal of the Acoustical Society of America, 45(1): 324-324. https://doi.org/10.1121/1.1971891

[6] Smith, G. (1989). A language for teaching discrete-event simulation. The Journal of the Operational Research Society, 40(9): 761-770. https://doi.org/10.1057/palgrave.jors. $\underline{0400903}$

[7] Chapelle, C.A. (2010). The spread of computer-assisted language learning. Language Teaching, 43(01): 66-74. https://doi.org/10.1017/s0261444809005850

[8] Amaral, L.A., Detmar, M. (2011). On using intelligent computer-assisted language learning in real-life foreign language teaching and learning. ReCALL, 23(1): 4-24. https://doi.org/10.1017/s0958344010000261

[9] Multhaup, U. (1997). Mental networks, procedural knowledge and foreign language teaching. Language Awareness, 6(2-3): 75-92. https://doi.org/10.1080/09658416.1997.9959919

[10] Harrison, R. (1998). The evolution of networked computing in the teaching of Japanese as a foreign language. Computer Assisted Language Learning, 11(4): 437-452. https://doi.org/10.1076/call.11.4.437.5667 
[11] Andrade, M.S. (2010). Teaching English as a foreign or second language: a selfdevelopment and methodology guide by Gerhard, jerry g. Modern Language Journal, 92(2): 337-338. https://doi.org/10.1111/j.1540-4781.2008.00729_14.x

[12] Hansen, J., Stansfield, C. (1982). Student-teacher cognitive styles and foreign language achievement: a preliminary study. Modern Language Journal, 66(3): 263-273. https://doi.org/10.1111/j.1540-4781.1982.tb06988.x

[13] Liou, H.C. (2012). The roles of $r$, second life $\backslash r$, in a college computer-assisted language learning (call) course in Taiwan, roc. Computer Assisted Language Learning, 25(4): 365 382. https://doi.org/10.1080/09588221.2011.597766

[14] Byrd, P. (2004). Review: teaching and researching computer-assisted language learning. Applied Linguistics, 25(4): 549-552. https://doi.org/10.1093/applin/25.4.549

[15] Last, R.W., King, P.K. (2010). The design and implementation of a computer assisted learning package for modern language teaching: a research progress report. British Journal of Educational Technology, 10(3): 194-197. https://doi.org/10.1111/j.14678535.1979.tb00384.x

[16] Brumen, M., Berro, F.F., Cagran, B. (2017). Pre-school foreign language teaching and learning - a network innovation project in Slovenia. European Early Childhood Education Research Journal, 1-14. https://doi.org/10.1080/1350293x.2017.1380886

[17] Politzer, R.L. (2010). Foreign language teaching and bilingual education: re-search implications. Foreign Language Annals, 13(4): 291-297. https://doi.org/10.1111/j.19449720.1980.tb01609.x

[18] Mcwilliams, A.T. (2010). Introducing expert systems to medical students using ESTA, expert system teaching aid. Medical Education, 22(2): 99-103. https://doi.org/10.1111/j.1365-2923.1988.tb00418.x

[19] Gibb, G., Lockwood, J.W., Naous, J., Hartke, P., Mckeown, N. (2008). Netfpga—an open platform for teaching how to build gigabit-rate network switches and routers. IEEE Transactions on Education, 51(3): 364-369. https://doi.org/10.1109/te.2008.919664

[20] Xue, L.J., Wang, L. (2011). Construction of university network teaching platform and application. 2011 International Conference on E-Business and E-Government, 7834-7836. https://doi.org/10.1109/icebeg.2011.5887060

[21] Li, Y.X., Zhang, F.X., Zhao, X., Cai, M.H., Hu, Y.K. (2010). Exploration and practice of genetics teaching assisted by network technology platform. Hereditas (Beijing), 32(4): 393-396. https://doi.org/10.3724/sp.j.1005.2010.00393

[22] Yalcin, N., Altun, Y., Kose, U. (2015). Educational material development model for teaching computer network and system management. Computer Applications in Engineering Education, 23(4): 621-629. https://doi.org/10.1002/cae.21636

[23] Schwarz, D. (2013). Interactive algorithms for teaching and learning acute medicine in the network of medical faculties MEFANET. Journal of Medical Internet Research, 15(7): e135. https://doi.org/10.2196/jmir.2590

[24] García, J., Entrialgo, J. (2015). Using computer virtualization and software tools to implement a low-cost laboratory for the teaching of storage area networks. Computer Applications in Engineering Education, 23(5): 715-723. https://doi.org/10.1002/cae.21644

[25] Maza-Ortega, J.M., Barragan-Villarejo, M., Garcia-Lopez, F.D.P., Jimenez, J., Mauricio, J., Alvarado-Barrios, L. (2017). A multi-platform lab for teaching and research in active distribution networks. IEEE Transactions on Power Systems, 32(6): 4861-4870. https://doi.org/10.1109/tpwrs.2017.2681182

[26] Frank, M.S., Gusé, S.L., Stern, E.J., Rohrmann, C.A. (1994). Integrating a digital dictation system with a network data base for creating and managing radiologic teaching files. In- 
vestigative Radiology, 29(6): 652-655. https://doi.org/10.1097/00004424-199406000$\underline{00011}$

[27] Fertuck, L. (1981). The tree system as a teaching aid in statistics, modeling and business courses. Computers \& Education, 5(1): 31-36. https://doi.org/10.1016/0360$\underline{1315(81) 90024-5}$

[28] Sawyer, J.A. (1981). The tree system as a teaching aid in macroeconomics and econometrics. Computers \& Education, 5(2): 101-110. https://doi.org/10.1016/0360-1315(81)900191

\section{Author}

Lei Zhang received the B.A. Degree in English teaching from Beihua University, Jilin, China, in 2002. the M.A. degree in comparative literature and world literature from Jilin University, Changchun, China, in 2008. M.A. degree in applied linguistics and ELT from St. Mary's University, London, the U.K., 2018. She has been on the faculty of Jilin Institute of Chemical Technology. Her research interests include English language teaching and British literature.

Article submitted 2019-04-13. Resubmitted 2019-05-19. Final acceptance 2019-04-27. Final version published as submitted by the authors. 